\title{
Application of Anodization to Reoxidize Silicon Nitride Film
}

\author{
Yen-Po LiN and Jenn-Gwo HwU* \\ Room 446, Department of Electrical Engineering, Graduate Institute of Electronics Engineering, National Taiwan University, \\ Taipei, Taiwan, Republic of China
}

(Received June 8, 2001; accepted for publication August 21, 2001)

\begin{abstract}
Anodic reoxidation of ultrathin $\mathrm{Si}_{3} \mathrm{~N}_{4}$ film in deionized (DI) water followed by rapid thermal annealing (RTA) in $\mathrm{N}_{2}$ (ANO) was for the first time studied in this work. The $\mathrm{Si}_{3} \mathrm{~N}_{4}$ film directly reoxidized in $\mathrm{O}_{2}$ by $\mathrm{RTA}\left(\mathrm{O}_{2} \mathrm{RTA}\right)$ was used for comparison. It was found that the reoxidation process could significantly improve the characteristics of chemical-vapor-deposited (CVD) $\mathrm{Si}_{3} \mathrm{~N}_{4}$ in terms of both the interface and bulk qualities. The ANO samples show lower leakage current, lower interface trap and bulk trap densities, and higher breakdown field than $\mathrm{O}_{2}$ RTA of the same equivalent oxide thickness (EOT). The better electrical characteristics of ANO are due to more oxygen atoms incorporated into the $\mathrm{Si}_{3} \mathrm{~N}_{4}$ films during the anodic reoxidation.
\end{abstract}

KEYWORDS: anodization, anodic reoxidation, nitride, XPS

\section{Introduction}

As the scaling of silicon complementary metal-oxide semiconductor (CMOS) devices shrinks further into the submicron range, thermally grown $\mathrm{SiO}_{2}$ with a thickness below $2 \mathrm{~nm}$ must be used as the gate dielectric to meet the high-performance requirement for the devices. The direct tunneling current becomes an important factor for limiting the reduction of oxide thickness. ${ }^{1)}$ Alternative insulator materials with a dielectric constant $k$ greater than 3.9 are therefore considered due to their increased physical thickness under the same capacitance with the thinner $\mathrm{SiO}_{2}$.

In finding alternative dielectric materials, silicon nitride films, such as oxynitride, ${ }^{2,3)}$ reoxidized nitride, ${ }^{4)}$ and jetvapor-deposited (JVD) nitride films, ${ }^{5-7}$ ) have been extensively studied because of their higher permittivity $(k=7.2)$ and more effective suppression of Boron penetration ${ }^{8)}$ into the substrate than silicon oxide films. However, thick silicon nitride films are known to have a high leakage current density, which is strongly related to its poor nitride film quality, e.g., too many charge traps and high interface state density. ${ }^{9}{ }^{9}$ However, in the ultrathin region (direct tunneling region), $\mathrm{Si}_{3} \mathrm{~N}_{4}$ film shows a markedly reduced number of charge trapping and enhanced detrapping of trapped charges due to tunneling, ${ }^{10)}$ both of which contribute to reduced leakage current and improved hot-carrier reliability. Furthermore, reoxidation of $\mathrm{Si}_{3} \mathrm{~N}_{4}$ films has been reported to reduce the electron trap density as well as suppress the interface-state generation under electrical stress. ${ }^{11)}$ It is noted that thin bottom oxides between $\mathrm{Si}_{3} \mathrm{~N}_{4}$ and $\mathrm{Si}$ can be formed during reoxidation of $\mathrm{Si}_{3} \mathrm{~N}_{4} \cdot{ }^{12)}$ However, the thickness of the bottom oxides that might limit the scaling of the effective dielectric thickness and degrade the time-dependent dielectric breakdown characteristic must be considered. ${ }^{13,14)}$ Many research studies were focused on the dominant charge carrier flow inside the nitride or oxidized nitride dielectrics, and it was found that electrons and holes are the dominant conduction carriers in the oxide and nitride, respectively. ${ }^{15)}$ It was also reported that when oxide was grown on the nitride, the hole flow through the nitride can be blocked by the oxide and hence the total gate leakage current is reduced. ${ }^{4)}$

In this work, we present a novel method of reoxidizing

*E-mail address: hwu@cc.ee.ntu.edu.tw the $\mathrm{Si}_{3} \mathrm{~N}_{4}$ film. Room-temperature anodic reoxidation in deionized (DI) water was used to reoxidize $\mathrm{Si}_{3} \mathrm{~N}_{4}$ for the first time. According to existing literature, ${ }^{16,17)}$ anodic oxides exhibit excellent electrical characteristics such as low leakage current, high dielectric breakdown field, and high effective electron barrier height. With the additional merits of low thermal budget and low cost, anodic oxidation is attractive in high-density integrated circuit application. It was found that $\mathrm{Si}_{3} \mathrm{~N}_{4}$ films prepared by anodic reoxidation show much- improved characteristics than the original chemical-vapor-deposited (CVD) $\mathrm{Si}_{3} \mathrm{~N}_{4}$. Also, they are better than the thermally reoxidized ones.

\section{Experiment}

To evaluate the effects of different reoxidation processes on $\mathrm{Si}_{3} \mathrm{~N}_{4}$, both anodic reoxidation and conventional thermal reoxidation were used in this study. Six-inch p-type Si wafers were used. After standard RCA cleaning with final HF dip, ultrathin $\mathrm{Si}_{3} \mathrm{~N}_{4}$ films of $2.5 \mathrm{~nm}$ thickness were formed with $\mathrm{SiH}_{2} \mathrm{Cl}_{2}$ and $\mathrm{NH}_{3}$ at $700^{\circ} \mathrm{C}$ by low-pressure chemical vapor deposition (LPCVD).

In the ANO procedure, the wafer with the $\mathrm{Si}_{3} \mathrm{~N}_{4}$ film acts as an anode. A constant electrolyzing voltage of $20 \mathrm{~V}$ was applied for 10 and 15 min separately at room temperature using DI water as an electrolyte. The schematic diagram of the anodic oxidation system is shown in Fig. 1. After the anodization procedure, post-anodic-oxidation rapid thermal annealing at $950^{\circ} \mathrm{C}$ for $30 \mathrm{~s}$ in $\mathrm{N}_{2}$ ambient was performed to induce hydrogen evolution from the oxidized nitride films. In rapid thermal annealing (RTA) in $\mathrm{O}_{2}$, i.e., $\mathrm{O}_{2} \mathrm{RTA}$, a conventional RTA system was utilized to oxidize the $\mathrm{Si}_{3} \mathrm{~N}_{4}$ films at $900^{\circ} \mathrm{C}$ and $950^{\circ} \mathrm{C}$ for $20 \mathrm{~s}$ in $\mathrm{O}_{2}$ ambient separately. In order to determine the atom distribution, the surface bonding condition and the atomic concentration, all the samples were examined by high-resolution secondary ion mass spectrometer (SIMS; Cameca, IMS-4f) and X-ray photoelectron spectroscopy (XPS; Physical Electronics, ESCA PHI 1600).

After the $\mathrm{Si}_{3} \mathrm{~N}_{4}$ reoxidation processes, aluminum of about $2000 \AA$ thickness was thermally evaporated on the front side surface and followed by photolithography to define the gate electrode. Then, backsurface metallization was implemented for the back contact of metal-oxidized nitride-Si capacitors. In addition, metal-oxide-Si (MOS) capacitors with thermal 


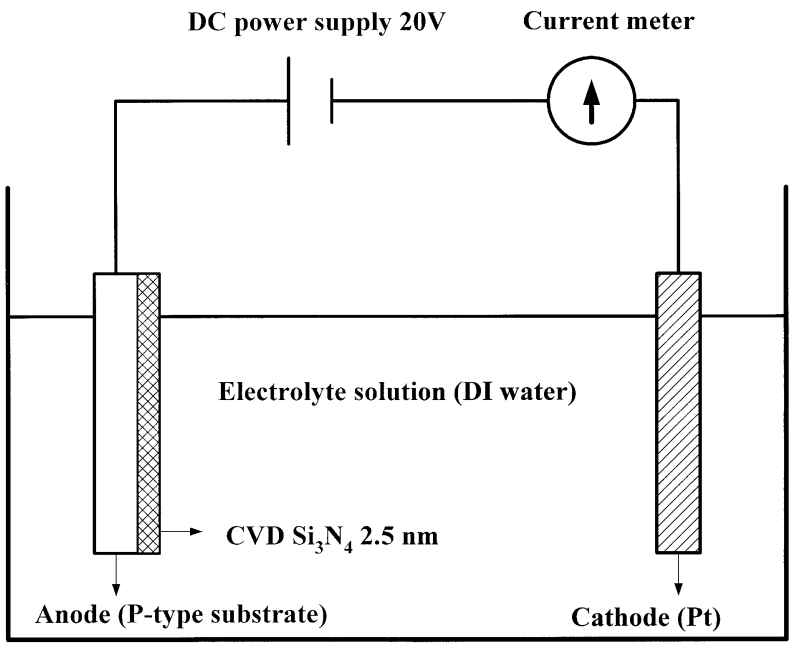

Fig. 1. Schematic diagram of anodic reoxidation system.

oxide layers of $2 \mathrm{~nm}$ thickness as the gate dielectric were also fabricated at the same time for comparison. Standard capacitance-voltage $(C-V)$ and current-voltage $(I-V)$ measurements were used to investigate the electrical properties of the devices. Also, the equivalent oxide thickness (EOT) was obtained from high-frequency $(100 \mathrm{KHz}) C-V$ measurements in strong accumulation region using a dielectric constant of 3.9, considering the quantum mechanism effect.

\section{Results and Discussion}

\subsection{Depth profile analysis}

Results of SIMS analysis of samples after different reoxidation processes of $\mathrm{Si}_{3} \mathrm{~N}_{4}$ films are shown in Fig. 2. In this figure, it is observed that no matter which reoxidation process was employed, very thin oxide buffer layers appear on the top and around the dielectric/silicon interface as shown by the accumulation of oxygen atoms. These interfacial buffer oxides can effectively improve the quality of the nitride interface by reducing the interface trap density. ${ }^{18)}$ In addition, the hole flow through the nitride faces a large barrier height due to the presence of interfacial oxide. ${ }^{15}$ ) The distributions of $\mathrm{Si}-\mathrm{N}$

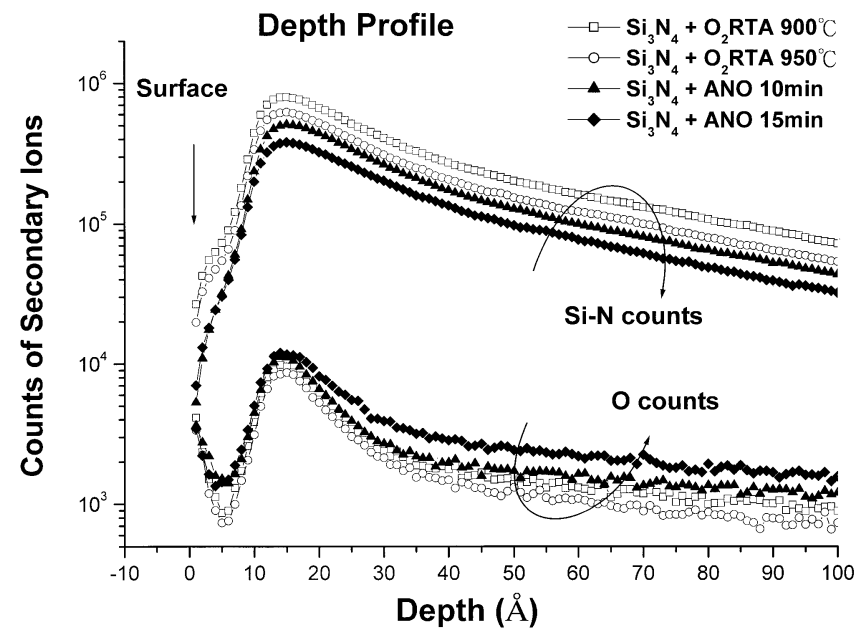

Fig. 2. SIMS depth profile of $\mathrm{Si}-\mathrm{N}$ and $\mathrm{O}$ counts for $\mathrm{Si}_{3} \mathrm{~N}_{4}$ samples after RTA reoxidation in $\mathrm{O}_{2}$ ambient $\left(\mathrm{O}_{2}\right.$ RTA $)$ and ANO. Cs ${ }^{+}$is used as sputtering ion in this analysis. and $\mathrm{O}$ atoms in the bulk and the surface are different between anodic reoxidation (ANO) and $\mathrm{O}_{2}$ RTA samples. We can observe that more oxygen atoms were incorporated into the films after anodic reoxidation. It is known that Frankel-Pool (F-P) emission is the main conduction mechanism of $\mathrm{Si}_{3} \mathrm{~N}_{4}$. Traps play an important role in the migration of carriers through the films. Also, the reoxidation of $\mathrm{Si}_{3} \mathrm{~N}_{4}$ films has been proposed to eliminate the electron traps. ${ }^{11)}$ It is therefore believed that these unwanted bindings or defects could be compensated during the reoxidation process, and more oxygen atoms incorporated in the films by anodic reoxidation could lead to the reduction in trap density and leakage current.

\subsection{Surface bonding analysis}

The surface bonding conditions after reoxidation of $\mathrm{Si}_{3} \mathrm{~N}_{4}$ films were characterized by ex situ XPS using monochromatic $\mathrm{Mg} \mathrm{K} \alpha$ radiation. Many research studies ${ }^{10,19)}$ indicated that the $\mathrm{N} 1 \mathrm{~s}$ with a peak energy of $397.99 \mathrm{eV}$ is mainly related to the formation of $\mathrm{N} \equiv \mathrm{Si}_{3}$ bonds and that of $398.6 \mathrm{eV}$ is $\mathrm{N}=\mathrm{Si}_{2}$. In the latter, each $\mathrm{N}$ atom is bonded to only two $\mathrm{Si}$ atoms with the remaining bond being a dangling bond. From these research studies, we found that in the presence of unwanted dangling bonds between the $\mathrm{S}-\mathrm{N}$ networks on the surface, the $\mathrm{N} 1 \mathrm{~s}$ peak energy position shifts to a higher energy level on the XPS spectra. Figure 3 shows the N $1 \mathrm{~s}$ spectra of the original CVD nitride and two reoxidized samples. In this figure, the original $\mathrm{Si}_{3} \mathrm{~N}_{4}$ peak energy position is located at $398.6 \mathrm{eV}$, indicating that a great amount of dangling bonds exist on the CVD nitride surface. It is observed that the peaks shift to a lower binding energy level after the reoxidation procedure. The binding energies are located at $397.7 \mathrm{eV}$ and $398.4 \mathrm{eV}$ for ANO and $\mathrm{O}_{2}$ RTA reoxidation, respectively. They are very close to those described above. From the spectra, we can observe that ANO reoxidation can convert the $\mathrm{Si}_{3} \mathrm{~N}_{4}$ films to be more stoichiometric than $\mathrm{O}_{2} \mathrm{RTA}$ reoxidation. It is believed that this formation of denser films is helpful in suppressing the boron penetration and reducing the boron-penetrationinduced low field leakage current. ${ }^{10)}$ The XPS data were analyzed by means of a standard software package to calculate the atomic concentration. $\mathrm{Si}_{3} \mathrm{~N}_{4}$ film not subjected to reoxidation was also taken into account in order to eliminate the

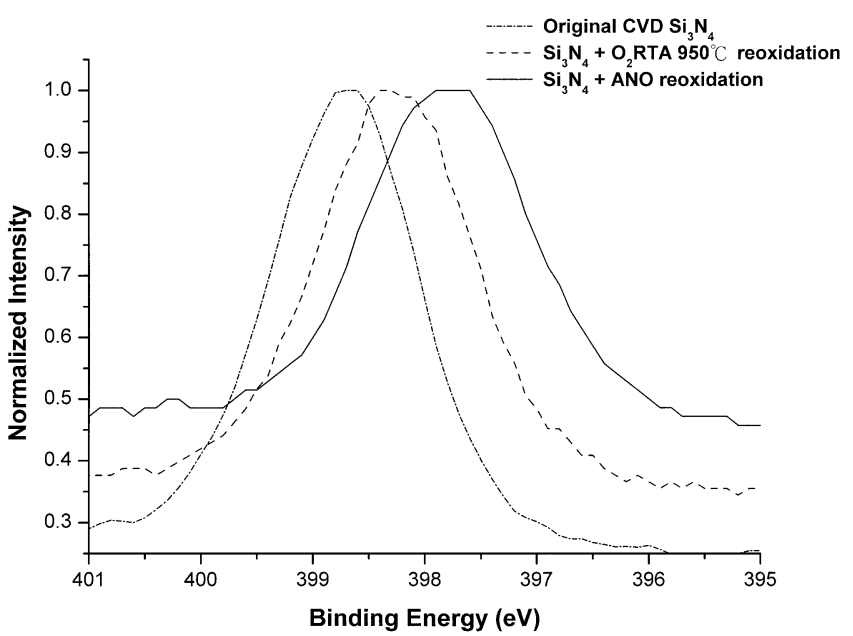

Fig. 3. Normalized N 1 s XPS spectra of $\mathrm{Si}_{3} \mathrm{~N}_{4}$ films after anodic reoxidation (solid line) and $\mathrm{O}_{2}$ RTA reoxidation (dash line). 


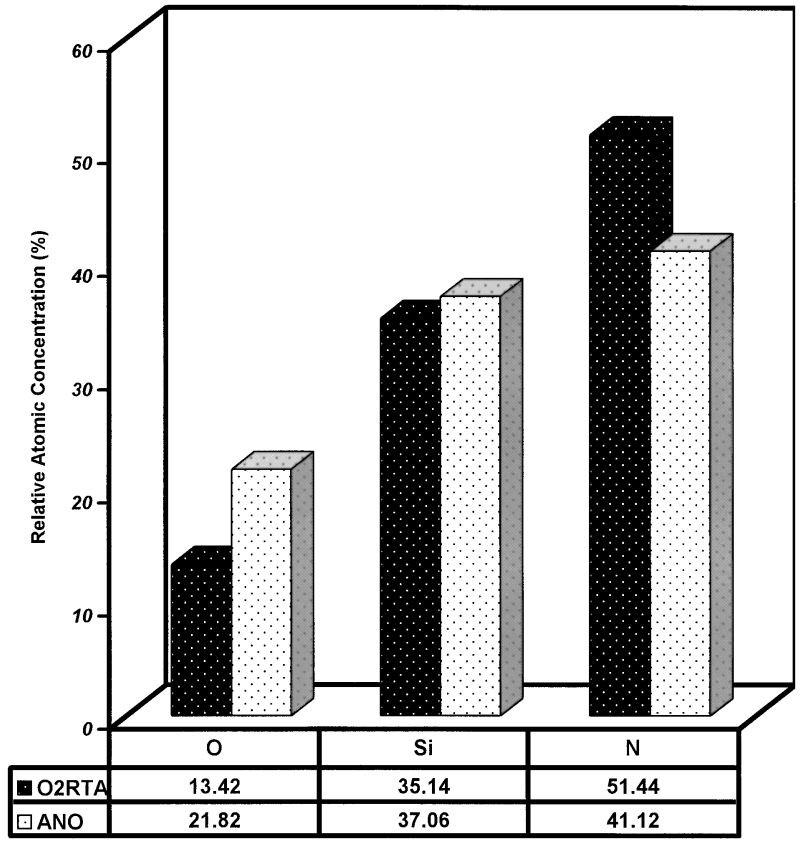

Fig. 4. Surface relative atomic concentrations $(\mathrm{O}, \mathrm{Si}$ and $\mathrm{N})$ in $\mathrm{Si}_{3} \mathrm{~N}_{4}$ films after $\mathrm{O}_{2}$ RTA and ANO

native oxide effect. As presented in Fig. 4, the concentration of the oxygen atoms in the ANO reoxidized sample (21.82\%) is obviously higher than that in the $\mathrm{O}_{2}$ RTA sample $(13.42 \%)$ on the surface. It is confirmed that more oxygen atoms can be incorporated into the $\mathrm{Si}_{3} \mathrm{~N}_{4}$ film by anodic reoxidation, and the traps and defects in the bulk oxide can be repaired during reoxidation.

\subsection{Characteristics of interface quality and leakage current}

Figures 5(a) and 5(b) show high-frequency $C-V$ curves of silicon nitride reoxidized by ANO and $\mathrm{O}_{2}$ RTA, respectively. For the sample $\mathrm{Si}_{3} \mathrm{~N}_{4}$ not subjected to any reoxidation treatment as shown in Fig. 5(c), its hysteresis loop is apparent, which may be attributed to the presence of electron traps in the interface. However, the hysteresis phenomenon becomes indistinguishable in the $C-V$ curves after the reoxidation treatment. We consider that both thermal and anodic

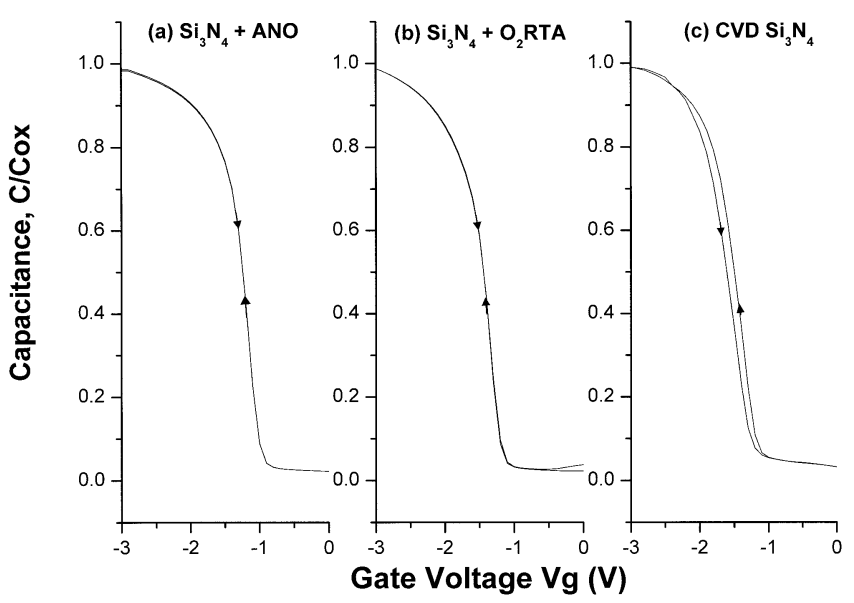

Fig. 5. $C-V$ characteristics of $\mathrm{CVD} \mathrm{Si}_{3} \mathrm{~N}_{4}$ (a) after anodic reoxidation $15 \mathrm{~min}$, (b) after $\mathrm{O}_{2} \mathrm{RTA}$ reoxidation at $950^{\circ} \mathrm{C}$, and (c) without any postdeposition treatment.

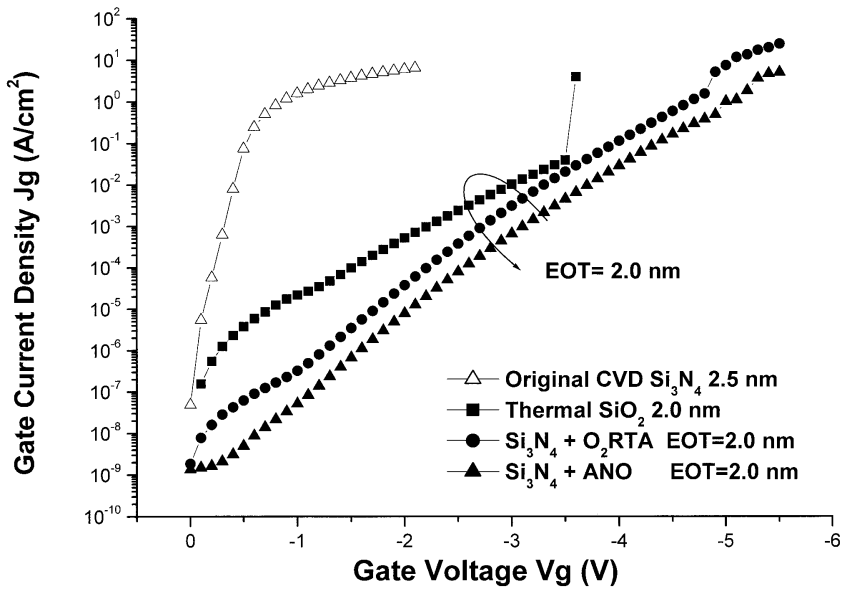

Fig. 6. $J-V$ characteristics of $\mathrm{SiO}_{2}, \mathrm{CVD} \mathrm{Si}_{3} \mathrm{~N}_{4}, \mathrm{Si}_{3} \mathrm{~N}_{4}+\mathrm{O}_{2} \mathrm{RTA}$, and $\mathrm{Si}_{3} \mathrm{~N}_{4}+$ ANO samples.

reoxidation processes can improve the interface quality by reducing the electron traps and interface state density since thin oxide buffer layers can be grown in the interface.

As the oxide thickness is reduced below $2.0 \mathrm{~nm}$ in the next generation, the rapid increase of direct tunneling current becomes a major obstacle for the scaling. Figure 6 shows the comparison of gate injection tunneling currents through the dielectrics of 2.0-nm-thick oxide layer and the nitride films after reoxidation processes of ANO and $\mathrm{O}_{2}$ RTA under the same equivalent oxide thickness (EOT) of $2.0 \mathrm{~nm}$. It is noted that the EOT value is defined by comparing the accumulation capacitance with that of the $\mathrm{SiO}_{2}$ sample. In addition, the original 2.5-nm-thick CVD $\mathrm{Si}_{3} \mathrm{~N}_{4}$ not subjected to reoxidation is also shown. From the current density-voltage $(J-V)$ curves, it is apparent that reoxidation can significantly improve the $\mathrm{CVD} \mathrm{Si}_{3} \mathrm{~N}_{4}$ quality by reducing the leakage current. It is also noted that the gate currents of $\mathrm{Si}_{3} \mathrm{~N}_{4}$ films after reoxidation are about 2-3 order of magnitude lower than that of the conventional $\mathrm{SiO}_{2}$ at a bias of $-1 \mathrm{~V}$, which can be attributed to their greater physical thickness than the oxide under the same EOT. Furthermore, the ANO-reoxidized sample shows a leakage current of an order of magnitude lower than that of the $\mathrm{O}_{2}$ RTA sample. It is believed that the ANO oxide grown on the surface of the $\mathrm{Si}_{3} \mathrm{~N}_{4}$ exhibits a more uniform electrical characteristic due to the self-compensation nature of the current path during anodization. A more uniform oxide exhibits less local thinning and therefore smaller leakage current. Meanwhile, ANO oxide with abundant oxygen atoms may reduce defect density in the bulk and therefore reduce the leakage current.

Figure 7 shows the comparison of time-zero-dielectricbreakdown (TZDB) characteristics of $\mathrm{SiO}_{2}, \mathrm{ANO}$ and $\mathrm{O}_{2} \mathrm{RTA}$ samples with EOT of $2.0 \mathrm{~nm}$. Compared with the conventional $\mathrm{SiO}_{2}$, the reoxidized $\mathrm{Si}_{3} \mathrm{~N}_{4}$ films show a higher $E_{\mathrm{bd}}$ of $24-26 \mathrm{MV} / \mathrm{cm}$ with EOT of $2.0 \mathrm{~nm}$. In addition, the ANO sample can suffer about $\sim 1 \mathrm{MV} / \mathrm{cm}$ more than the $\mathrm{O}_{2} \mathrm{RTA}$ sample before breakdown. It is believed that the reduction of electron traps in the ANO sample makes the breakdown via the electron-trapping mechanism difficult.

It is known that the trapping of positive charges under a constant current stress will result in a reduction in gate voltage, while that of negative charges an increase in gate volt- 


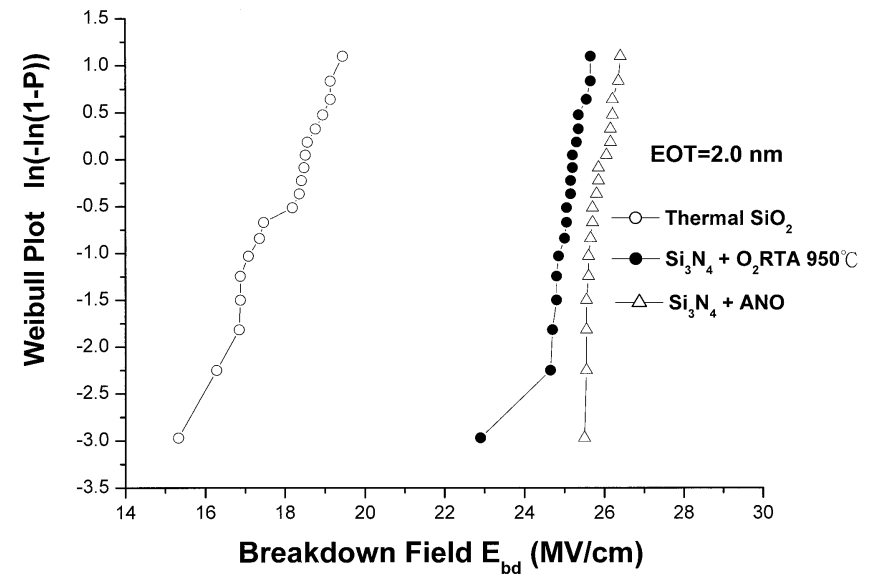

Fig. 7. Weibull plot of equivalent breakdown field for $\mathrm{SiO}_{2}, \mathrm{Si}_{3} \mathrm{~N}_{4}+\mathrm{O}_{2} \mathrm{RTA}$, and $\mathrm{Si}_{3} \mathrm{~N}_{4}+$ ANO samples.

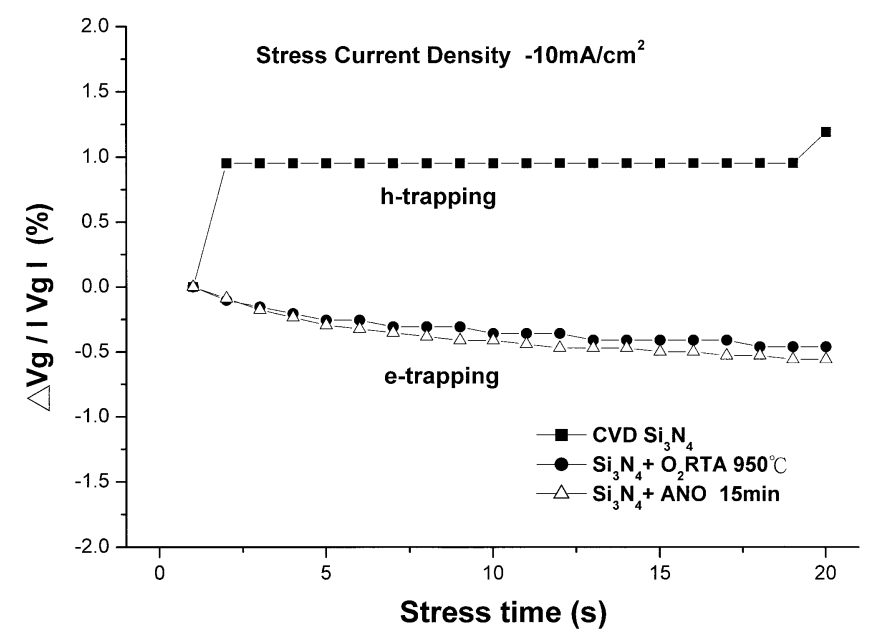

Fig. 8. Variations of $\Delta V_{\mathrm{g}} /\left|V_{\mathrm{g}}\right|$ versus stress time under a constant current density of $-10 \mathrm{~mA} / \mathrm{cm}^{2}$ for $\mathrm{Si}_{3} \mathrm{~N}_{4}, \mathrm{Si}_{3} \mathrm{~N}_{4}+\mathrm{O}_{2} \mathrm{RTA}$, and $\mathrm{Si}_{3} \mathrm{~N}_{4}+$ ANO samples.

age. ${ }^{20)}$ Figure 8 shows the variation of $V_{\mathrm{g}}$ under a $-10 \mathrm{~A} / \mathrm{cm}^{2}$ current density stress. It shows a different trapping mechanism in that the original $\mathrm{Si}_{3} \mathrm{~N}_{4}$ film contains a great amount of hole traps with respect to the reoxidized $\mathrm{Si}_{3} \mathrm{~N}_{4}$ films. The latter exhibit net electron traps. We can note that the ANO sample presents a slightly more shift under stress. This is because the anodic reoxidation was performed in the liquid state. More $\mathrm{OH}^{-}$ion related to the chemical species can be incorporated into the films than thermally grown oxide. It was reported that the dangling bonds in the silicon nitride are passivated by hydrogen. ${ }^{21)}$ Also, it is known that the chemical species of $-\mathrm{NH}_{x},-\mathrm{OH}$, and $-\mathrm{H}$ act as electron traps in the oxide. ${ }^{22)}$ A trade-off must be considered by controlling the hydrogen concentration in reoxidized $\mathrm{Si}_{3} \mathrm{~N}_{4}$ to compensate for the hole traps in $\mathrm{Si}_{3} \mathrm{~N}_{4}$. However, the hydrogen problem is not serious for the ANO sample as compared with that of the $\mathrm{O}_{2}$ RTA one.

\section{Conclusions}

Characteristics of reoxidized $\mathrm{Si}_{3} \mathrm{~N}_{4}$ by anodization were for the first time studied in this work. Reoxidation could obvi- ously improve the $\mathrm{Si}_{3} \mathrm{~N}_{4}$ quality including reduced interface trap and bulk trap densities based on the results of $C-V$ and $I-V$ measurements. It was found that the anodic reoxidation has the merits of lower leakage current, lower interface state density, and higher breakdown field compared with thermal reoxidation. It was shown that $\mathrm{O}$ atoms are easier to be incorporated into the $\mathrm{Si}_{3} \mathrm{~N}_{4}$ film by anodic reoxidation. In addition, we can observe that $-\mathrm{H}$ related to chemical species of the film might cause electron traps in the dielectric, which compensate the hole traps in the $\mathrm{Si}_{3} \mathrm{~N}_{4}$ film. The anodic reoxidation appears to be an efficient method of preparing high-quality ultrathin reoxidized high- $k$ dielectrics.

\section{Acknowledgements}

The authors want to thank the NTHU Instrument Center for supporting SIMS and ESCA analyses and the National Science Council of Republic of China for supporting this work under contract no. NSC-89-2215-E002-042.

1) B. Yu, H. Wang, C. Riccobene, Q. Xiang and M. R. Lin: Proc. Symp. VLSI Technology, 2000, p. 90.

2) C. Gerardi, M. Melanotte, S. Lombardo, S. Lombardo, M. Alessandri, B. Crivelli and R. Zonca: J. Appl. Phys. 87 (2000) 498.

3) G. Lucovsky, H. Niimi, Y. Wu, C. R. Parker and J. R. Hauser: J. Vac. Sci. \& Technol. A 16 (1998) 1721.

4) M. K. Mazumder, K. Kobayashi, J. I. Mitsuhashi and H. Koyama: IEEE Trans. Electron Devices 41 (1994) 2417.

5) Y. C. Yeo, Q. Lu, W. C. Lee, T. J. King, C. Hu, X. Wang, X. Guo and T. P. Ma: IEEE Electron Device Lett. 21 (2000) 540.

6) T. P. Ma: IEEE Trans. Electron Devices 45 (1998) 680

7) S. Mahapatra, V. Ramgopal Rao, K. N. Manjularani, C. D. Parikh, J. Vasi, B. Cheng and M. Khare: Proc. Symp. VLSI Technology, 1999, p. 79.

8) Y. Wu and G. Lucovsky: IEEE 36th Annu. Int. Reliability Physics Symp., 1998, p. 70.

9) H. Iwai, Y. Ozawa, K. T. Morimoto, H. S. Momose, Y. Ozawa and K. Yamabe: IEDM Tech. Dig., 1990, p. 235.

10) B. Y. Kim, H. F. Luan and D. L. Kwong: IEDM Tech. Dig., 1997, p. 463.

11) W. Yang, R. Jayaraman and C. G. Sodini: IEEE Trans. Electron Devices 37 (1988) 939.

12) S. C. Song, H. F. Luan, C. H. Lee, A. Y. Mao, S. J. Lee, J. Gelpey, S. Marcus and D. L. Kwong: Proc. Symp. VLSI Technology, 1999, p. 137.

13) K. Ando, A. Ishiyani and K. Hamano: Appl. Phys. Lett. 59 (1991) 1081.

14) N. Ajika, M. Ohi, H. Arima, T. Matsukawa and N. Tsubouchi: Proc. Symp. VLSI Technology, 1991, p. 63.

15) M. Aminzadeh, S. Nozaki and R. V. Giridhar: IEEE Trans. Electron Devices 35 (1988) 459.

16) M. J. Jeng and J. G. Hwu: Appl. Phys. Lett. 69 (1996) 3875.

17) J. S. Liu, M. C. Chiang, C. L. Chen and T. Y. Huang: IEEE Proc. 7th IPFA, 1999, p. 34.

18) C. G. Parker, G. Lucovsky and J. R. Hauser: IEEE Electron Device Lett. 19 (1998) 106.

19) R. I. Hegde, P. J. Tobin, K. G. Reid, B. M. Maiti and S. A. Ajuria: Appl. Phys. Lett. 66 (1995) 2882.

20) M. S. Lian, C. Chang, Y. T. Yeow, C. Hu and R. W. Brodersen: IEEE Trans. Electron Devices 31 (1984) 1238.

21) K. Sekine, Y. Saito, M. Hirayama and T. Ohmi: J. Vac. Sci. \& Technol. A 17 (1999) 3129.

22) M. Bhat, G. W. Yoon, J. Kim and D. L. Kwong: Appl. Phys. Lett. 64 (1994) 2116. 